\title{
Sperm competition and offspring viability at hybridization in Australian tree frogs, Litoria peronii and L. tyleri
}

\author{
CDH Sherman ${ }^{1}$, E Wapstra ${ }^{2}$ and M Olsson ${ }^{1}$ \\ ${ }^{1}$ School of Biological Sciences, The University of Wollongong, Wollongong, New South Wales, Australia and ${ }^{2}$ School of Zoology, \\ University of Tasmania, Hobart, Tasmania, Australia
}

\begin{abstract}
Hybridization between closely related species often leads to reduced viability or fertility of offspring. Complete failure of hybrid offspring (post-zygotic hybrid incompatibilities) may have an important role in maintaining the integrity of reproductive barriers between closely related species. We show elsewhere that in Peron's tree frog, Litoria peronii, males more closely related to a female sire more offspring in sperm competition with a less related rival male. Observations of rare 'phenotypic intermediate' males between $L$. peronii and the closely related $L$. tyleri made us suggest that these relatedness effects on siring success may be because of selection arising from risks of costly hybridization between the two species. Here, we test this hypothesis in an extensive sperm competition experiment, which shows that there is no effect of species identity on probability of fertilization in sperm
\end{abstract}

competition trials controlling for sperm concentration and sperm viability. Instead, there was a close agreement between a male's siring success in isolation with a female and his siring success with the same female in competition with a rival male regardless of species identity. Offspring viability and survival, however, were strongly influenced by species identity. Over a 14-day period, hybrid offspring suffered increasing mortality and developed more malformations and an obvious inability to swim and right themselves, leading to compromised probability of survival. Thus, hybridization in these sympatric tree frogs does not compromise fertilization but has a strong impact on offspring viability and opportunity for reinforcement selection on mate choice for conspecific partners.

Heredity (2010) 104, 141-147; doi:10.1038/hdy.2009.118; published online 2 September 2009

Keywords: hybridization; offspring fitness; sperm competition; genetic relatedness; fertilization

\section{Introduction}

The production of unfit offspring through hybridization of incipient species is predicted to result in selection for reproductive isolating barriers that reduce the risk of hybridization (Arnold, 1997; Coyne and Orr, 1998). Reproductive isolating barriers may arise at three different levels (1) premating (that is, mating/pollinator behavior, timing of gamete release/flowering times), (2) post-insemination/pollination (gamete recognition) and (3) post-fertilization (offspring viability, survivorship and sterility; Arnold, 1997). Isolation barriers that act between copulation and fertilization have until recently received little attention; however, there is growing evidence that they can have an important role in speciation (for example, Palumbi, 1994; Vacquier, 1998). The investigation of barriers to hybridization at a level of gametic compatibility was, however, for considerable time fraught with the limitation of being non-competitive (Arnold, 1997, 2006). In other words, crosses normally involved the fertilization of a female with a heterospecific male but not with a conspecific male. However, in

Correspondence. Current address: Dr CDH Sherman, School of Life and Environmental Sciences, Deakin University, Waurn Ponds, Wollongong, Victoria 3217, Australia.

E-mail: csherman@deakin.edu.au

Received 27 March 2009; revised 26 June 2009; accepted 13 July 2009; published online 2 September 2009 natural populations, females are expected to be exposed to sperm/pollen from both con- and heterospecific males (Arnold, 1997, 2006). More recently, experiments on heterospecific gamete competition, primarily in plants and insects, have revealed a variety of outcomes in staged trials in the laboratory. These experiments have resulted in full heterospecific gametic compatibility, assessed in terms of proportional fertilization success, when heterospecific gametes are brought together in isolation. However, when a female is mated with both a heterospecific and conspecific male (therefore allowing sperm competition between con- and heterospecific sperm), conspecific males often secure a greater proportion of fertilizations (Arnold, 1997, 2006 and references therein). For example, in two races of grasshoppers (Podisma pedestris spp.), there is sperm precedence for first males. However, when this is taken into account, conspecific males sire significantly more offspring (Hewitt et al., 1989). In this case, the difference in siring success took place at the pre-fertilization level (Hewitt et al., 1989). In another grasshopper crossing experiment, this time between Chorthippus parallelus parallelus and C. $p$. erythropus, there were significantly more pure progeny produced compared with hybrid progeny. There was, however, also evidence of second male sperm precedence, possibly due to sperm ageing or differential storage and use of sperm by the female (Bella et al., 1992). Work on crickets (Allonemobius sp.) show similar results 
with poorer motility of heterospecific sperm stored in the spermathecae of females, resulting in lower fertilization success compared with conspecific males (Gregory and Howard, 1994). Work by Wade and Johnson (1994) and Wade et al. (1994) shows very similar conspecific dominance in siring success in Tribolium beetles, as do marine organisms (for example, sea urchins Geyer and Palumbi, 2005) and some plants (for example, Rieseberg et al., 1995), although the underlying mechanisms differ (reviewed in Arnold, 1997, 2006).

When hybrid fertilization takes place, the next level of selection will be on the viability of the hybrid offspring. Historically, the views on the importance of successful hybridization in terms of evolutionary change has been all across the continuum from Lotsy $(1916,1931)$ arguing its dominating importance in evolution to Dobzhansky (1937, p. 231) claiming that 'no hybrids reach reproductive stage'. Clearly, the reality lies somewhere in between these views with successful introgression of genes occurring at least occasionally during hybridization between species and which generates greater fitness in hybrid offspring compared with purebred offspring. An example of this is (at least sometimes) the case of the fire-bellied toads (Vines et al., 2003, but see Nurnberger et al., 2005). Another set of examples come from hybridization resulting in new, successful species of Lake Malawi cichlids as a result of genetic mosaicism (Salzburger et al., 2002; Seehausen et al., 2003; Seehausen, 2004). Finally, one of the most detailed studies showed that hybridization effects on offspring viability can be sex-specific, consistent with Haldane's rule. Female (heterogametic) flycatchers resulting from crossings between Ficedula hypoleuca and F. albicollis showed sterility as a result of incompatibility between maternally transmitted mtDNA and paternal nuclear genes, whereas males remained fertile (Tegelström and Gelter, 1990; Saetre et al., 2003). In this case, the sex chromosomes also contained genes that affect species recognition and concomitant compromised offspring viability as a result of 'poor' mate choice.

The current study builds on our previous observation of a fertilization advantage of males more closely related with a female in staged artificial fertilization trials in the Australian tree frog, Litoria peronii (Sherman et al., 2008b). An implicit assumption in this study was that of compromised offspring viability in hybrid matings with the sympatric L. tyleri, much to the same effect as the recently described ongoing speciation between lineages of another Australian tree frog, L. genimaculata (Hoskin et al., 2005). We test here the hypotheses that (i) hybridization compromises probability of paternity in sperm competition, (ii) hybrid embryos have lower hatching success than purebred embryos and (iii) posthatching development and survival carries a cost at hybridization. We use the results from our laboratory trials, and observations of 'intermediate phenotypes' between $L$. peronii and $L$. tyleri in the wild, for making evolutionary inferences on reproductive barriers between the two species in the wild.

\section{Materials and methods}

\section{Study species}

The Australian tree frog, L. peronii, occurs throughout the coastal and inland regions of New South Wales (NSW), southern Queensland and northern Victoria (Cogger, 2000; Griffiths, 2006). The range of L. tyleri is restricted to mainly coastal areas of NSW and southern Queensland within the range of L. peronii (Cogger, 2000; Griffiths, 2006). Both species are commonly found occupying the same breeding ponds, although one species is often numerically dominant (Sherman $\mathrm{CDH}$ personal observation). Morphologically, the two frogs are very similar but L. peronii can be distinguished from $L$. tyleri by more intense yellow and black mottling in its thighs and armpits. The vocal sack of L. tyleri is often a more intense yellow during the breeding season compared with that of L. peronii (Sherman CDH personal observation). The two species have distinct mating calls, which may be important in mate choice. L. peronii males are, however, indiscriminate choosers and have been observed amplexing males of the same species and even individuals of different species. Observations of matings and the success of naturally spawned clutches between these two species have not been observed directly; however, the presence of rare 'phenotypic intermediate' males between $L$. peronii and $L$. tyleri suggests that successful natural hybridization does occur, at least occasionally.

We collected adult male and female L. peronii from a single pond at Darkes Forest, NSW, Australia $\left(34^{\circ} 13^{\prime} \mathrm{S}\right.$, $150^{\circ} 55^{\prime} \mathrm{E}$ ). Male L. tyleri were collected from a nearby population (approximately 35 kilometers apart) at Yeramba Lagoon, Sydney $\left(33^{\circ} 58^{\prime} S, 151^{\circ} 00^{\prime} \mathrm{E}\right)$. Both species occur at both locations, although $L$. peronii is the numerically dominant species at Darkes Forest, whereas L. tyleri is the more common species at Yeramba Lagoon. Individuals of the two species were collected from different locations for logistic reasons, as only sufficient numbers of each species could be collected on the same night by targeting different locations. Only vocalizing males were captured, indicating that they were ready to mate and likely to be reproductively mature (Sherman et al., 2008a, b). Gravid female L. peronii were collected during their migration from surrounding vegetation to the breeding pond. Insufficient females L. tyleri were found during the collections, limiting our crosses to $L$. peronii and L. tyleri males with $L$. peronii females. Frogs were transported to laboratory facilities at the University of Wollongong where we held males overnight at room temperature. Females were held at 10 $12{ }^{\circ} \mathrm{C}$ to prevent the spontaneous release of gametes. For each frog we measured snout-vent length, to the nearest millimeter, and mass to the nearest $0.01 \mathrm{~g}$. All frogs were used for in vitro fertilization experiments within $24 \mathrm{~h}$ of capture, and were released back to their place of capture within $72 \mathrm{~h}$.

\section{In vitro fertilizations and sperm competition trials}

We followed the protocol for artificial fertilizations for L. peronii outlined by Sherman et al. (2008b). Briefly, 30 independent sperm competition and control fertilization trials were carried out using sperm collected from one randomly chosen male $L$. peronii and one randomly chosen male $L$. tyleri with a randomly chosen female L. peronii (Figure 1). We induced males to release sperm after a subcutaneous injection of luteinizing hormone releasing hormone (Sigma-Aldrich, Sydney, New South Wales, Australia). Approximately, $150 \mu \mathrm{l}$ per $10 \mathrm{~g}$ body weight of a $5 \mathrm{mg}$ per $100 \mathrm{ml}$ luteinizing hormone 


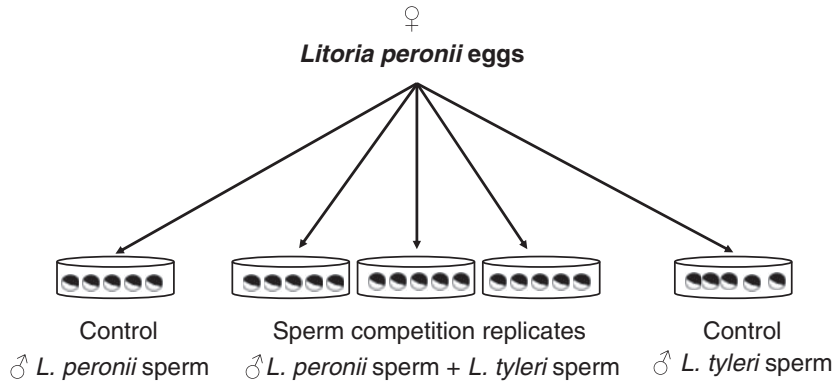

Figure 1 Experimental design of in vitro fertilization trials. Sperm competition trials contain equal numbers of sperm from Litoria peronii and $L$. tyleri males mixed with $L$. peronii eggs. Control fertilizations contain sperm from each male in isolation mixed with L. peronii eggs.

releasing hormone in isotonic saline solution $(0.9 \% \mathrm{NaCl})$ was injected into the lymph sacs of the flanking region. Males were injected within 2 min of each other to ensure that longevity of sperm did not confound our experiments. Frogs were placed in conical flasks and kept in a dark room for $40 \mathrm{~min}$ before sperm, which is passively released from the frog's cloaca, was collected from the bottom of the conical flask. The conical flask was subsequently flushed with $2 \mathrm{ml}$ of aged water and the resulting sperm suspension was collected using a sterile pipette. A small aliquot $(100 \mu \mathrm{l})$ of each male's sperm was taken to determine the proportion viable sperm using Live/Dead sperm viability kits as per the manufactures instructions (Invitrogen, Molecular Probes, Mount Waverley, Victoria, Australia). Sperm concentration for each male was determined using a Hawksley hemocytometer (improved Neubauer, $0.1 \mathrm{~mm}$ in depth, Crown Scientific, Minto, New South Wales, Australia) with the sperm samples diluted to equal concentrations (sperm concentration varied between trials from $3.2 \times 10^{5}-4.0 \times 10^{6}$ sperm cells per ml). This sperm concentration was within the range known to produce high rates of fertilization within this species, resulting in $1.9 \times 10^{3}-2.4 \times 10^{5}$ sperm per egg. For each sperm competition trial, $3 \mathrm{ml}$ of standardized sperm solution from each of the two males were mixed together $(6 \mathrm{ml}$ total) by gentle pipetting. This mixture was then divided between three replicate Petri dishes ( $2 \mathrm{ml}$ of the mixed sperm solution per dish). A control Petri dish for each male received sperm from only one male $(2 \mathrm{ml})$ and was used to assess each male's ability to fertilize a female's eggs in the absence of sperm competition (Figure 1). Approximately 100 eggs (mean $104 \pm 2.2$ s.e.) from a randomly chosen female were harvested directly into each Petri dish by gently squeezing her abdomen. After 2-3 min, the egg/sperm mixture was flooded with $100 \mathrm{ml}$ of aged water. After $3 \mathrm{~h}$, all eggs were transferred to a $750 \mathrm{ml}$ plastic container with aged water and held at a constant temperature of $23^{\circ} \mathrm{C}$ until hatching. Of the 30 trials, one trial failed completely, indicating unviable eggs and this trial was excluded from further analysis.

\section{Assignment of paternity}

From each of the three sperm competition replicates, 15 hatchlings were collected (mean number of hatchlings per trial $42 \pm 4$ s.d.) and preserved in $95 \%$ ethanol before DNA extraction. A toe clip from each adult in the sperm competition trials was used for DNA extraction and the assignment of paternity. Genomic DNA was isolated from whole tadpoles using Qiagen DNAeasy Tissue Kits (Qiagen, Doncaster, Victoria, Australia) as per the manufacturer's instructions. All samples were amplified for nine polymorphic microsatellite loci (LP01, LP03, LP04, LP05, LP07, LP13, LP19, LP22 and LP23) originally designed for $L$. peronii (see Sherman and Olsson (2007) for PCR conditions). Of the nine loci, four (LP07, LP13, LP19 and LP22) successfully cross-amplified in L. tyleri, with no indication of null alleles detected from the progeny arrays. Paternity was unambiguously assigned to all offspring (1200 tadpoles) according to allele sharing between putative sires, dam and offspring using these four loci. The remaining five loci varied from partial amplification of some alleles (LP03 and LP05) to no amplification at all (LP01, LP04 and LP23) with L. tyleri sires.

\section{Assessment of tadpole fitness}

We compared fertilization success, hatching success, survivorship and viability of purebred $L$. peronii tadpoles and hybrid tadpoles (L. peronii eggs $\times$ L. tyleri sperm) from the control crosses. The proportion of eggs successfully fertilized for each replicate was assessed $48 \mathrm{~h}$ post fertilization when developing embryos could be distinguished from unfertilized eggs (stages 15-18; Gosner, 1960). Hatching success for both species was assessed 7 days after fertilization (Anstis, 2002) as the proportion of fertilized eggs that successfully hatched. Survivorship and viability was assessed at 9 and 14 days after hatching. Survivorship was assessed as the proportion of tadpoles alive at each sampling period. Tadpole viability was assessed as the proportion of tadpoles with normal morphology, swimming behavior and ability to right themselves in a resting position.

\section{Statistical analyses}

We assessed differences in fertilization and hatching success in the control and sperm competition trials using analysis of variance (One-Way ANOVA (analysis of variance)). All variables met the assumptions of normality and homogeneity of variances.

The difference in male siring success between the two heterospecific males ( $L$. peronii and $L$. tyleri) in sperm competition was assessed using a General Linear Model (Proc GLM, SAS 9.1). Fertilization success in control Petri dishes, the proportion of viable sperm within each male's ejaculate and genetic similarity of each male relative to the female were included as main predictors in the model. All variables except the proportion of viable sperm within a male's ejaculate met the assumptions of normality and homogeneity of variances. After an arcsine square root transformation of the proportion of viable sperm the data met the assumptions of normality and equal variances.

Differences in survivorship and viability of purebred and hybrid tadpoles from the control fertilizations were analyzed using a General Linear Mixed Model (Proc MIXED, SAS 9.1). Female identity number was entered as a random factor and male species identity, and day (measurements taken at day 9 and 14) as fixed factors. Random effects were tested using likelihood ratio tests, fixed effects using F-tests, and the degrees of freedom were estimated using Satterthwaite's approximation (Littell et al., 1996). 


\section{Results}

\section{Fertilization and hatching success}

Fertilization and hatching success in both the sperm competition and control trials were high (overall mean \pm s.e. $73 \% \pm 3 \%$; Figures $2 \mathrm{a}$ and $\mathrm{b}$ ). We found no significant difference in fertilization and hatching success between heterospecific $\left(L\right.$. peronii $i_{\text {eggs }} \times L_{\text {. }}$ tyleri $\left._{\text {sperm }}\right)$ and
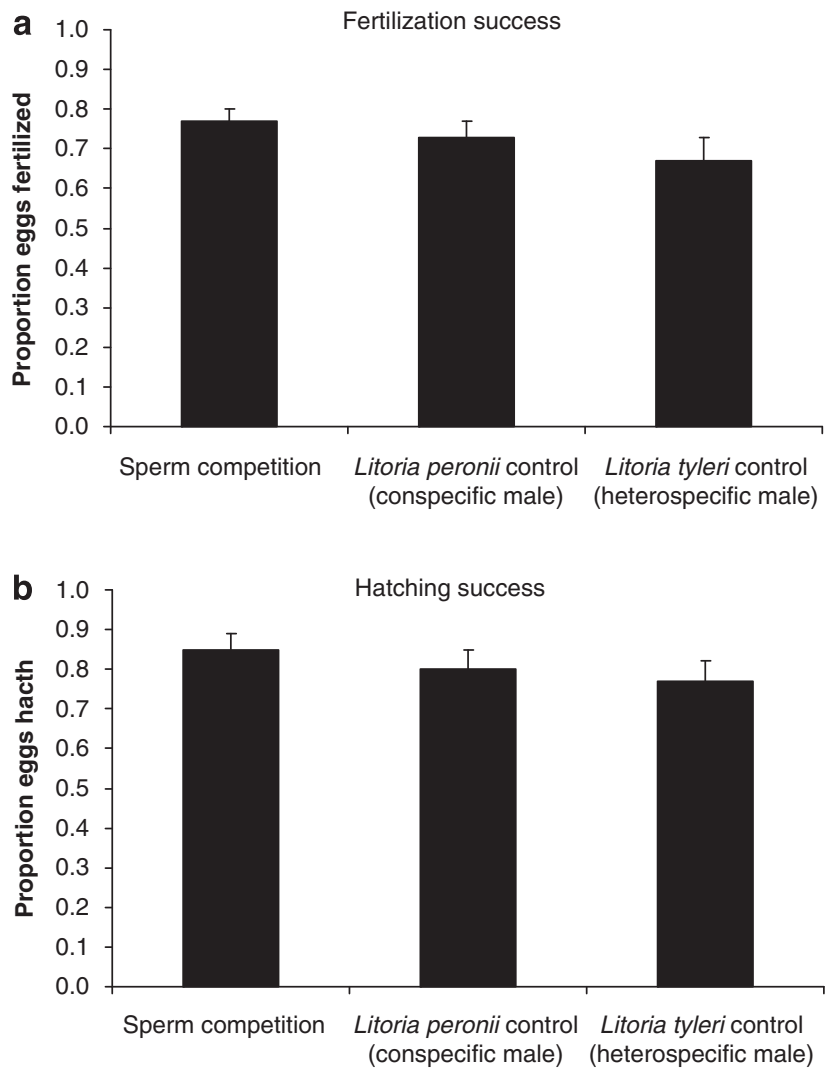

Figure 2 Fertilization (a) and hatching (b) success of male Litoria peronii and L. tyleri with female L. peronii in sperm competition and control trials. Controls contain sperm from each male in isolation. conspecific (L. peronii $i_{\text {eggs }} \times L$. peronii $i_{\text {sperm }}$ ) fertilizations in the control or sperm competition trials (One-Way ANOVA fertilization success: $F_{2,82}=1.31, P=0.28$; hatching success: $F_{2,82}=1.23, P=0.30$; Figures $2 \mathrm{a}$ and $\mathrm{b}$ ).

\section{Siring success}

Siring success in sperm competition trials was highly skewed ( $>70 \%$ siring success) toward one of the two competing males for 21 out of the 29 trials. For 10 of the sperm competition trials, fertilization success was skewed toward the conspecific male (L. peronii), whereas in 11 of the sperm competition trials fertilization success was skewed toward the heterospecific male (L. tyleri). For the remaining eight trials, siring success was approximately equal for both con- and heterospecific males (Figure 3).

Our GLM (general linear model) analysis showed that the only trait that significantly influenced a male's relative siring success in sperm competition was the fertilization success of that particular male in the control fertilizations (that is, when sperm from each male and species were allowed to fertilize eggs from a L. peronii female in isolation; Table 1). A pairwise $t$-test of a deviation from zero male difference in siring success within female identity number confirmed the result of no difference in siring success between the two species (mean $=-0.045$, s.e. $=0.14, n=29, P=0.75$ ).

\section{Survivorship and offspring viability}

Survivorship and offspring viability was significantly lower for hybrid tadpoles compared with that for purebred tadpoles in the control fertilizations both at 9 and 14 days post hatching (Figures 4 and 5). The mixed model ANOVAs of the proportion of surviving tadpoles and their viability showed the strongest effects of hybridization, then day of assessment (with increasing severity toward the last day, 14, of the experiment, Table 2, Figures 4 and 5). Lastly, there was no effect of female identity on either of these response variables.

\section{Discussion}

Our results clearly indicate that the barrier to hybridization between these species lies at the level of developmental

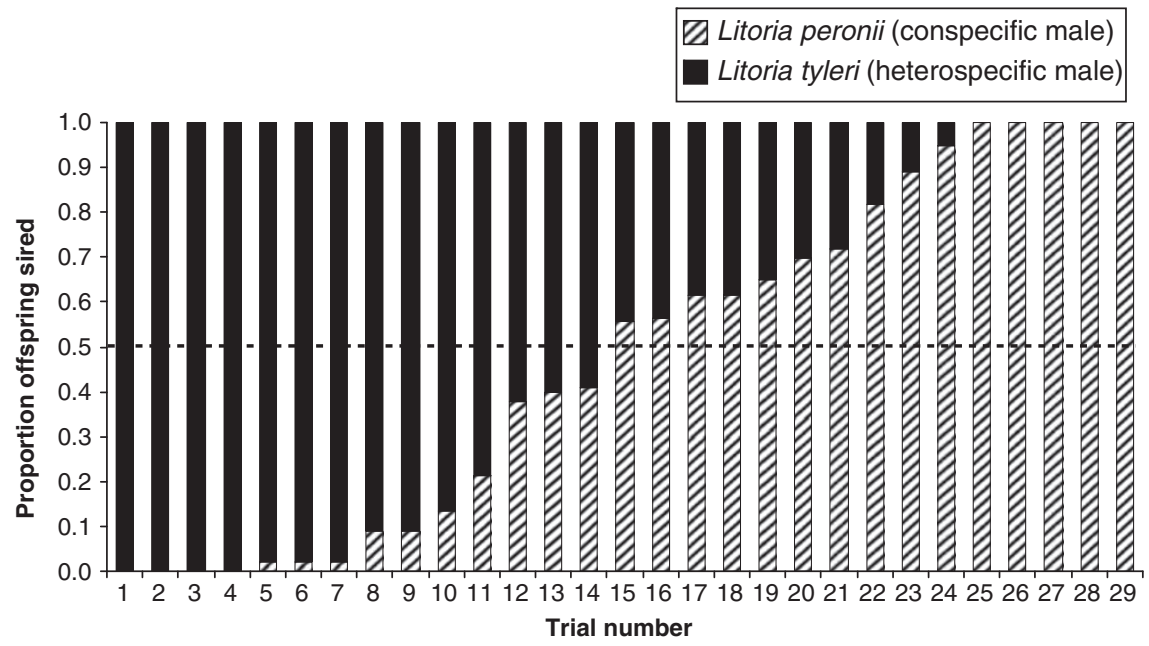

Figure 3 The proportion of offspring sired by either conspecific male (hatched) or heterospecific male (black) in 29 sperm competition trials with standardized sperm numbers. Dotted line represents the 50:50 share of paternity expected under the null hypothesis of equal fertilization ability of competing sperm. 
Table 1 Multiple regression analysis of predictors of siring success between a male L. peronii and L. tyleri in sperm competition trials

\begin{tabular}{|c|c|c|c|c|}
\hline \multicolumn{5}{|c|}{ Response variable: difference in siring success between L. peronii and L. tyleri } \\
\hline Predictors & $\beta$ & s.e. & $t$ & P-value \\
\hline Fertilization success in isolation & 1.54 & 0.18 & 4.22 & 0.0003 \\
\hline Proportion alive sperm & 0.40 & 0.72 & 0.55 & 0.585 \\
\hline Relatedness with female & -0.09 & 0.91 & -0.10 & 0.919 \\
\hline
\end{tabular}

Model $R^{2}=0.46, F_{3,24}=6.90, P=0.0016$. $\beta$, regression coefficient; s.e., standard error of regression coefficient.

The predictors are modeled as the difference in trait values between L. peronii and L. tyleri (i.e., as is the response variable siring success).

a

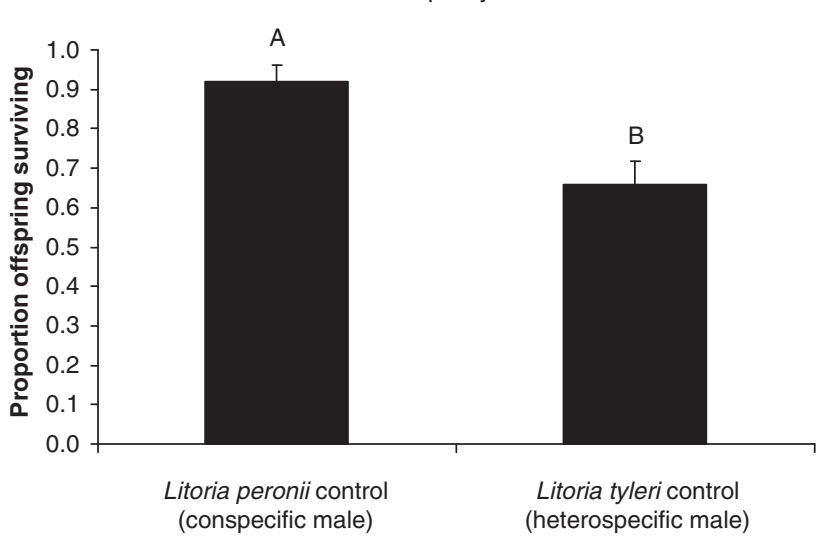

b

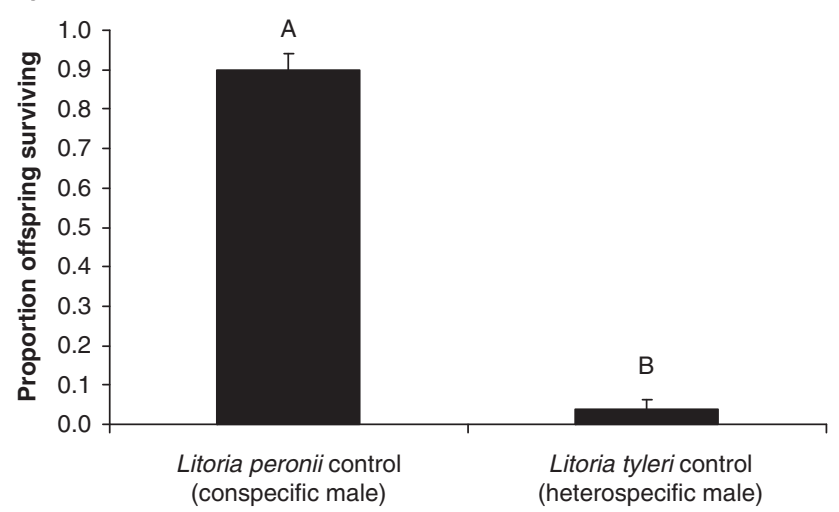

Figure 4 Proportion of purebred and hybrid tadploes surviving to day 9 (a) and day 14 (b) post-hatching from control fertilizations. Significant difference between purebred and hybrid tadpoles indicated by scripts above standard error bars.

stability and offspring survival rather than at fertilization and gametic fusion. Several hypotheses could explain these results. First, anuran amphibians communicate acoustically and, although unstudied in these species, potential mate choice based on acoustic quality is likely to be important. If so, there may have been limited selection for hybrid avoidance at the gametic level, and our laboratory trials may therefore represent an enforced fertilization process with the risk of overstating its importance in the wild. However, our observations of 'intermediate phenotype' males, that is males showing lack of typical body and throat coloration of either of the two species, suggests that occasionally hybridization may occur and that some male $\times$ female genetic interactions across the species may survive to adulthood.
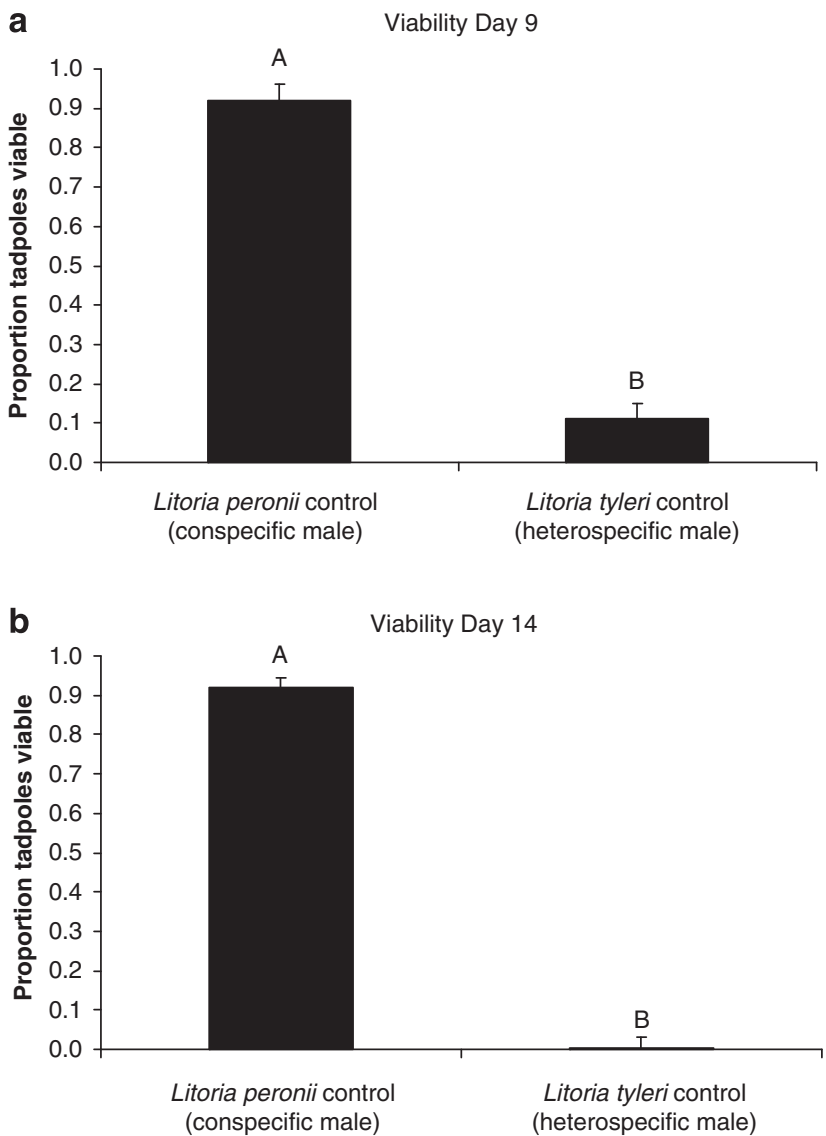

Figure 5 Proportion of viable purebred and hybrid tadpoles at day 9 (a) and day 14 (b) post-hatching from control fertilizations. Significant difference between purebred and hybrid tadpoles indicated by scripts above standard error bars.

Furthermore, the fact that L. peronii males more closely related with the female have a fertilization advantage also suggests that the risk of hybridization is real in the wild (Sherman et al., 2008b). We were, however, surprised at the complete hybrid compatibility at the gametic level-especially in a situation of sperm competition with another species. Unlike our results, previous studies have shown a conspecific sire advantage (Bella et al., 1992; Wade and Johnson, 1994; Wade et al., 1994; Rieseberg et al., 1995; Geyer and Palumbi, 2005). Previous work on amphibian cross-fertilization has also shown wide among-species compatibility at the fertilization level. However, in the toads Bufo arenarum, B. paracnemis and Lepidactylus chaquencis, this was followed by high levels of polyspermy and disturbed ontogenetic devel- 
Table 2 Results from mixed model ANOVAs with species and day as fixed factors and female identity number as random factor using restricted maximum likelihood (REML)

\begin{tabular}{lcccc}
\hline \multicolumn{5}{c}{ Type 3 tests of fixed effects } \\
\hline Effect & Num d.f. & Den d.f. & $F$ & P-value \\
\hline Response variable: & proportion live tadpoles & & \\
Species & 1 & 85 & 133.2 & $<0.0001$ \\
Day & 1 & 85 & 34.0 & $<0.0001$ \\
Random effect: female number, $\chi^{2}=1.08$, d.f. $=1,0.1, P>0.5$ \\
Response variable: proportion viable tadpoles \\
Species \\
1 & 84 & 648.5 & $<0.0001$ \\
Day & 1 & 85 & 0.7 & 0.40 \\
Random effect: female number, $\chi^{2}=1.1$, d.f. $=1,0.1, P>0.5$ \\
\hline
\end{tabular}

The significance of the random factor was assessed using log likelihood ratio tests against a $\chi^{2}$ distribution with d.f. $=1$. Days $=9$ or 14 days, Species $=L$. peronii or L. tyleri.

opment (Gómez and Cabada, 1994). Another wellcharacterized hybrid system is that of the European water frogs, Rana lessonae and $R$. ridibunda, resulting in the hybrid species R. esculenta (Berger, 1977; Abt and Reyer, 1993; Engeler and Reyer, 2001). A study by Reyer et al. (2003) showed no precedence for conspecific sperm over heterospecific sperm when sperm from the two parental species ( $R$. lessonae and $R$. ridibunda) compete for fertilizations, consistent with the results from this study. However, hybrid $R$. esculenta males consistently have lower fertilization success in sperm competition trials with the two parental species, but this could not be attributed to the quality of sperm or a taxon-specific eggsperm recognition system (Reyer et al., 2003). Thus, being highly acoustic species, these observations agree with the hypothesis of a perhaps stronger (but unquantified) selection for pre-gametic hybrid avoidance and less opportunity for selection at a gametic compatibility level. In contrast, work on grasshoppers and crickets (reviewed in Arnold (1997, 2006)), which are equally acoustic species in terms of sexual communication, still show conspecific sperm precedence and, hence, this explanation does not apply to all taxa. Some of the fastest evolving and most sophisticated gamete recognition systems have been described in marine, sessile organisms, and which are known to have an important role in preventing hybridization or fertilization by incompatible partners (reviewed in Swanson and Vacquier (1998)). Our results provide no direct evidence for such taxonspecific gamete recognition system between these two species. Surprisingly, we also found no evidence that the proportion of viable sperm within a male's ejaculate affects siring success in sperm competition or in the single-species fertilizations (controls). This is consistent with our previous study on sperm competition in L. peronii (Sherman et al., 2008b), which showed that the only significant predictor of siring success in sperm competition trials is the corresponding success of males in control fertilizations. This suggests that some unmeasured intrinsic property of a male's sperm (or semen) is important in determining a male's siring success at fertilization.

Owing to the logistic constraints, our study is limited to assessing the consequences of an asymmetric hybrid breeding design,that is, between two different species of male frogs (L. peronii and L. tyleri) with females from only one of these species (L. peronii). There are numerous examples from the wild in which hybridization results in reduced fitness consequences in only one sex (for example, flycatchers, Ficedula sp.; Tegelström and Gelter, 1990). In our laboratory study, most hybrids were unviable after 14 days. This contrasts with our observations from the wild of phenodeviants that best can be described as adult intermediates between the two species and, hence, natural rates of hybrid viability may be higher if fertilization success and offspring viability had been investigated with a complete and balanced, symmetric breeding design. Such mortality effects of offspring from a given, but not opposite-sex partner, have been reported for several species of plants and animals (Arnold et al., 1996; Coyne and Orr, 1998; Funk, 1998; Tiffin et al., 2001; Coyer et al., 2002) and may well explain a discrepancy in mortality between field and laboratory bred animals in the current study.

In conclusion, our study shows that gamete recognition and fertilization pose no barrier to hybridization between female $L$. peronii and male $L$. tyleri. However, selection against hybridization through offspring viability is strong and surviving young are unlikely to be sired by male $L$. tyleri and female L. peronii.

\section{Acknowledgements}

We thank Ken Griffiths for help with fieldwork, and the Fahey family for access to breeding ponds at Darkes forest. We thank the Australian Research Council for financial support. MO would like to dedicate this work to the memory of Prof. Håkan 'HåTe' Tegelström, Uppsala, Sweden, taken from us far too early, and who surely still would have had a lot to say about hybridization and genetic introgression.

\section{References}

Abt G, Reyer HU (1993). Mate choice and fitness in a hybrid frog-Rana esculenta-females prefer Rana lessonae males over their own. Behav Ecol Sociobiol 32: 221-228.

Anstis M (2002). Tadpoles of South-Eastern Australia. Reed New Holland: Sydney.

Arnold ML (1997). Natural Hybridization and Evolution. Oxford University Press: Oxford.

Arnold ML (2006). Evolution Through Genetic Exchange. Oxford University Press: Oxford.

Arnold SJ, Verrell PA, Tilley SG (1996). The evolution of asymmetry in sexual isolation: a model and a test case. Evolution 50: 1024-1033.

Bella JL, Butlin RK, Ferris C, Hewitt GM (1992). Asymmetrical homogamy and unequal sex-ratio from reciprocal matingorder crosses between Chorthippus parallelus subspecies. Heredity 68: 345-352.

Berger L (1977). Systematics and hybridization in the Rana esculenta complex. In: Taylor DH, Guttmann S (eds). The Reproductive Biology of Amphibians. Plenum: New York. pp 367-388.

Cogger H (2000). Reptiles and Amphibians of Australia, 6th edn. Read New Holland: Sydney.

Coyer JA, Peters AF, Hoarau G, Stam WT, Olsen JL (2002). Hybridization of the marine seaweeds, Fucus serratus and Fucus evanescens (Heterokontophyta: Phaeophyceae) in a 100-year-old zone of secondary contact. Proc R Soc B Biol Sci 269: 1829-1834. 
Coyne JA, Orr HA (1998). The evolutionary genetics of speciation. Philos Trans $R$ Soc Lond B Biol Sci 353: 287-305.

Dobzhansky T (1937). Genetics and the Origin of Species. Columbia University Press: New York.

Engeler B, Reyer HU (2001). Choosy females and indiscriminate males: mate choice in mixed populations of sexual and hybridogenetic water frogs (Rana lessonae, Rana esculenta). Behav Ecol 12: 600-606.

Funk DJ (1998). Isolating a role for natural selection in speciation: host adaptation and sexual isolation in Neochlamisus bebbianae leaf beetles. Evolution 52: 1744-1759.

Geyer LB, Palumbi SR (2005). Conspecific sperm precedence in two species of tropical sea urchins. Evolution 59: 97-105.

Gómez MI, Cabada MO (1994). Amphibian cross-fertilization and polyspermy. J Exp Zool 269: 560-565.

Gosner KL (1960). A simplified table for staging anuran embryos and larvae with notes on identification. Herpetologica 16: 183-190.

Gregory PG, Howard DJ (1994). A postinsemination barrier to fertilization isolates two closely-related ground crickets. Evolution 48: 705-710.

Griffiths K (2006). Frogs and Reptiles of the Sydney Region. New Holland: Sydney.

Hewitt GM, Mason P, Nichols RA (1989). Sperm precedence and homogamy across a hybrid zone in the alpine grasshopper Podisma pedestris. Heredity 62: 343-353.

Hoskin CJ, Higgie M, McDonald KR, Moritz C (2005). Reinforcement drives rapid allopatric speciation. Nature 437: 1353-1356.

Littell RC, Millikrn GA, Stroup WW, Wolfinger RD (1996). SAS System for Mixed Models. SAS Instistute Inc: Cary, NC.

Lotsy JP (1916). Evolution by Means of Hybridization. Martinus Nijhoff: The Hague.

Lotsy JP (1931). On the species of the taxonomist in its relation to evolution. Genetica 13: 1-16.

Nurnberger B, Barton NH, Kruuk LEB, Vines TH (2005). Mating patterns in a hybrid zone of fire-bellied toads (Bombina): inferences from adult and full-sib genotypes. Heredity 94: 247-257.

Palumbi SR (1994). Genetic divergence, reproductive isolation, and marine speciation. Annu Rev Ecol Syst 25: 547-572.

Reyer HU, Niederer B, Hettyey A (2003). Variation in fertilisation abilities between hemiclonal hybrid and sexual parental males of sympatric water frogs (Rana lessonae, R. esculenta, R. ridibunda). Behav Ecol Sociobiol 54: 274-284.

Rieseberg LH, Desrochers AM, Youn SJ (1995). Interspecific pollen competition as a reproductive barrier between sympatric species of Helianthus (Asteraceae). Am J Bot 82: 515-519.

Saetre GP, Borge T, Lindroos K, Haavie J, Sheldon BC, Primmer C et al. (2003). Sex chromosome evolution and speciation in Ficedula flycatchers. Proc $R$ Soc Lond B Biol Sci 270: 53-59.

Salzburger W, Baric S, Sturmbauer C (2002). Speciation via introgressive hybridization in East African cichlids? Mol Ecol 11: 619-625.

Seehausen O (2004). Hybridization and adaptive radiation. Trends Ecol Evol 19: 198-207.

Seehausen O, Koetsier E, Schneider MV, Chapman LJ, Chapman CA, Knight ME et al. (2003). Nuclear markers reveal unexpected genetic variation and a Congolese-Nilotic origin of the Lake Victoria cichlid species flock (vol 270, pg 129, 2003). Proc $R$ Soc Lond B Biol Sci 270: 2637-2638.

Sherman C, Olsson M (2007). Polymorphic microsatellite loci in the Australian tree frog, Litoria peronii. Conserv Genet 8 : 999-1001.

Sherman CDH, Wapstra E, Uller T, Olsson M (2008a). Male and female effects on fertilization success and offspring viability in the Peron's tree frog, Litoria peronii. Austral Ecol 33: 348-352.

Sherman CDH, Wapstra E, Uller T, Olsson M (2008b). Males with high genetic similarity to females sire more offspring in sperm competition in Peron's tree frog Litoria peronii. Proc $R$ Soc B Biol Sci 275: 971-978.

Swanson WJ, Vacquier VD (1998). Mechanism for evolution of species-specific fertilization. Mol Biol Cell 9: 312A-312A.

Tegelström H, Gelter HP (1990). Haldane rule and sex biased gene flow between two hybridizing flycatcher species (Ficedula albicollis and F. hypoleuca, Aves: Muscicapidae). Evolution 44: 2012-2021.

Tiffin P, Olson MS, Moyle LC (2001). Asymmetrical crossing barriers in angiosperms. Proc $R$ Soc Lond B Biol Sci 268: 861-867.

Vacquier VD (1998). Evolution of gamete recognition proteins. Science 281: 1995-1998.

Vines TH, Kohler SC, Thiel A, Ghira I, Sands TR, MacCallum CJ et al. (2003). The maintenance of reproductive isolation in a mosaic hybrid zone between the fire-bellied toads Bombina bombina and B-variegata. Evolution 57: 1876-1888.

Wade M, Patterson H, Chang N, Johnson N (1994). Postcopulatory, prezygotic isolation in flour beetles. Heredity 72: 163-167.

Wade MJ, Johnson NA (1994). Reproductive isolation between 2 species of flour beetles, Tribolium castaneum and T. freemani: variation within and among geographical populations of T. castaneum. Heredity 72: 155-162. 